\title{
UN MOSAICO DE LENGUAS: \\ LOS INTÉRPRETES DE \\ LA AUDIENCIA DE MÉXICO \\ EN EL SIGLO XVI
}

\author{
Caroline Cunill \\ Université $d u$ Maine
}

CONSIDERACIONES HISTORIOGRÁFICAS Y METODOLÓGICAS

$\mathrm{D}$ ebido al creciente interés por el uso estratégico que hicieron los pueblos indígenas del sistema de justicia colonial, así como por la adaptación del Imperio hispánico al reto que representaba la presencia de poblaciones cultural y lingüísticamente diversas, los oficios de "agentes mediadores" han ido cobrando especial relevancia en la historiografía americanista. ${ }^{1}$ En los últimos años se han multiplicado los estudios enfocados en los defensores de indios, los procuradores, los abogados, los escribanos y, evidentemente, en los intérpretes. De este modo, hoy contamos con los trabajos de Puente Luna, Yannakakis, Cunill, Payas y Zavala, Nansen Díaz, Jurado y Machuca

Fecha de recepción: 4 de abril de 2017

Fecha de aceptación: 7 de agosto de 2017

${ }^{1}$ Véanse, entre otros, Gayol, Laberintos de justicia, 2 vols.; Herzog, Mediación; Burns, Into the Archive; Dueñas, “The Lima Indian"; Mijares RamíReZ, Escribanos; YannaKakis, The Art of Being in-Between. 
sobre los intérpretes de las Audiencias de Lima, Oaxaca, Yucatán, Michoacán, el Río de la Plata Chile, y Colima, respectivamente. ${ }^{2}$ Está claro que los avances de una antropología jurídica centrada en los derechos lingüísticos de las poblaciones autóctonas no fueron ajenos a este desarrollo historiográfico, puesto que ambas corrientes se hacen eco desde temporalidades distintas. ${ }^{3}$ También existe una rica historiografía acerca de la política lingüística de la corona española, con los trabajos de Durston y Hanks sobre la traducción en el contexto misionero, de Swchaller, Christensen y Cobo Betancourt sobre el uso de las lenguas autóctonas por el clero, y de Estenssoro e Itier sobre la expansión de las "lenguas generales” en el Imperio hispánico. ${ }^{4}$ Estas investigaciones han permitido completar las propuestas más teóricas producidas por Zavala, Solano y Karttunen en los años anteriores. ${ }^{5}$

Pero, pese a estos notables avances, todavía no existe ningún estudio sistemático sobre los intérpretes de las lenguas autóctonas que sirvieron en la Audiencia de México en el siglo XVI. En realidad, sólo se encuentran referencias aisladas acerca de aquellos oficiales en obras enfocadas en otras temáticas. Así, por ejemplo, aunque en Law and Transformation of Aztec Culture Kellog insiste en el papel de mediación desempeñado por los intérpretes en este tribunal, no identifica a ninguno de

2 Puente Luna, "The Many Tongues"; Yannakakis, "Making Law Intelligible"; Cunill, "Los intérpretes de Yucatán” y "Justicia e interpretación"; Nansen Díaz, "Los intérpretes jurados"; Jurado, "Don Pedro de Dueñas"; Payas y Zavala (eds.), La mediación lingüístico-cultural; MachuCA, Intérpretes y trasuntos.

${ }^{3}$ Véanse Yrigoyen Fajardo, Justicia y multilingüismo; Ordóñez Cifuentes (coord.), El derecho a la lengua.

${ }^{4}$ Durston, Pastoral Quechua; Hanks, Converting Words; Schwaller, "The Expansion of Nahuatl"; Christensen, "The Use of Nahuatl”; Сово Betancourt, "Colonialism in the Periphery"; Estenssoro e ItIer, "Langues indiennes".

${ }^{5}$ Zavala, Poder y lenguaje; Solano, El intérprete; KartTunen, Between Worlds. 
los titulares del cargo. ${ }^{6}$ Del mismo modo, en su libro sobre el Juzgado General de Indios, Borah se limita a mencionar algunos elementos formales relativos al salario y funciones de estos oficiales. ${ }^{7}$ En Empire of Law and Indian Justice, Owensby identifica a dos intérpretes que sirvieron de forma puntual en averiguaciones realizadas en Tehuantepec y Malacatepec. ${ }^{8}$ Romero Galván apunta, por su lado, que don Fernando de Alvarado Tezozomoc, descendiente de don Diego de Alvarado Huanitzin y juez gobernador del cabildo indígena de México, pudiera haber sido intérprete en la Audiencia de México. ${ }^{9}$ En After Moctezuma, Connell señala que Juan Grande fue intérprete en el pleito con el cabildo indígena de México en 1564 y que Jerónimo de León, gobernador indígena interino después de la muerte de Juan Valeriano en 1620, también fue nahuatlato. ${ }^{10}$ Finalmente, en su libro sobre el cabildo indígena de Tenochtitlan Rovira Morgado incluye datos biográficos sobre el intérprete Hernando de Tapia. ${ }^{11}$

En este panorama, tanto el artículo de Carrasco titulado "Indian-Spanish Marriages", como la monografía Reshaping New Spain de Ruiz Medrano resultan de especial interés. En efecto, en el primer trabajo, el autor observa que varios intérpretes en la Audiencia de México fueron conquistadores españoles casados con mujeres indígenas. Según él, éste fue el caso de Juan Pérez de Arteaga, casado con la hija de un cacique

\footnotetext{
${ }^{6}$ Kellogg, Law and Transformation, pp. 23-24.

7 Borah, El Juzgado General de Indios, pp. 109, 114 y 238.

${ }^{8}$ Owensby, Empire of Law, pp. 190 y 254.

${ }^{9}$ Romero Galván, Los privilegios perdidos, pp. 82-94.

${ }_{10}$ Connell, After Moctezuma, pp. 27 y 113. Connell cita las fuentes siguientes: AGN, I, vol. 5, exp. 595 y AGN, C, vol. 644, exp. 1.

${ }^{11}$ Hernando de Tapia era el hijo primogénito de don Andrés de Tapia Motelchiuhtzin, quaubtlabtoani de México-Tenochtitlán entre 1525/1526 y 1530. Hernando de Tapia se había casado con una mujer castellana, llamada Isabel de Cáceres. Rovira Morgado, San Francisco Padremeh, pp. 104-106. Véase también Rovira Morgado, "La 'Casa de Tapia'”, 13 pp.
} 
de Tlaxcala; de Antonio Ortiz, esposo de doña Isabel, hija de un principal de Tlaxcala; de Juan Freyle, casado con la hija del gobernador de Texcoco; y de Juan Grande, marido de doña Francisca Verdugo Ixtlilxochitl, hija del cacique de Teotihuacan y nieta del rey Ixtlilxóchitl de Texcoco. El autor añade que, en la década de 1570, los mestizos Martín Gómez, Diego de León, Pedro López de Barahona y Rodrigo Gutiérrez, ocuparon el oficio de intérprete en la Audiencia. ${ }^{2}$ Basándose en los juicios de residencia de Francisco de Loaysa (1535-1536), Francisco Tello de Sandoval (1543-1547) y Diego López de Montealegre (15531560), Ruiz Medrano también identifica a varios intérpretes que sirvieron en la Audiencia. ${ }^{13}$ Señala que Pedro García fue intérprete de la segunda Audiencia y que el jardinero del licenciado Lorenzo de Tejada, llamado Francisco de Triana, desempeñó actividades informales de traducción en beneficio del oidor. ${ }^{14}$ Asimismo, muestra que los intérpretes Hernando de Tapia, Antonio Ortiz, Tomás de Rijoles y Pedro de Molina participaron en transacciones de compraventa o de intercambio de tierras realizadas entre los indígenas y el citado oidor entre 1540 y 1543 y que, a cambio de su actitud favorable a los intereses económicos de Tejada, los tres primeros recibieron mercedes de tierras en la región de Tacuba-Chapultepec. ${ }^{15}$ En Mexico's Indigenous Communities Ruiz Medrano menciona el nombre de

\footnotetext{
12 Carrasco, "Indian-Spanish Marriages", pp. 87-104. El autor menciona que, durante la visita realizada por Tello de Sandoval en 1546, el licenciado Tejada pretendió defenderse de las acusaciones de los intérpretes Antonio Ortiz, Francisco Triano y Marcos Romero, su primo, tachando al primero de pagano y mal cristiano y a los otros dos de moriscos. AGI, J, 260. Visita de Tello de Sandoval (1546-1547).

${ }_{13}$ Ruiz Medrano, Reshaping New Spain. La autora cita las fuentes siguientes: AGI, J, 232. Residencia del licenciado Francisco de Loaysa (1535-1536). AGI, $J$, 260. Visita del licenciado Francisco Tello de Sandoval (1543-1547). AGI, J, 237, Residencia del licenciado Diego López de Montealegre (1553-1560).

${ }_{14}$ Ruiz Medrano, Reshaping New Spain, pp. 26, 176 y 183.

15 Ruiz Medrano, Reshaping New Spain, pp. 158, 163, 170 y 192.
} 
siete nahuatlatos que servían en la Audiencia de México hacia 1590 - Juan de Riberol, Juan Grande, Pedro López de Barahona, Juan Méndez de Sotomayor, Francisco de [Leiva?], Bernardino de Leiva y Nicolás de Castro- y advierte la presencia en aquel tribunal de intérpretes de otomí y de mixteco. ${ }^{16}$

Aunque estos trabajos brindan datos sobre la identidad étnica, vínculos familiares y relaciones sociales de varios intérpretes de la Audiencia de México en el siglo xvi, todavía hace falta una investigación sistemática que permita ofrecer una visión más precisa del oficio y de sus titulares. ¿Qué lenguas autóctonas se hablaban en la Audiencia de México además del náhuatl? ¿Quién desempeñó las funciones de intérprete? ¿Eran indígenas, españoles o mestizos? ¿En qué condiciones estos actores llegaron a ser bilingües? Para contestar a estas interrogantes, el presente artículo analiza 13 nombramientos de intérpretes otorgados por la Audiencia de México entre 1555 y $1606 .{ }^{17}$ Esta información se cruza con los datos contenidos en ocho probanzas de méritos y servicios que algunos titulares del cargo mandaron al Consejo de Indias, de manera individual o colectiva, para pedir remuneración y confirmación de su oficio. ${ }^{18} \mathrm{La}$ reconstrucción de estas series documentales permite esclarecer no sólo la política lingüística de la corona y el proceso de adaptación de las instituciones del Imperio hispánico a la

\footnotetext{
${ }^{16}$ Ruiz Medrano, Mexico's Indigenous Communities, pp. 67-68. Ruiz Medrano utiliza como fuentes las cartas del virrey Velasco al rey, México, 25 de mayo y 28 de octubre de 1591, 20 de febrero y 6 de marzo de 1592. AGI, $A M, 22$.

${ }^{17}$ Las referencias exactas de aquellos nombramientos están sintetizadas en el cuadro 1.

18 AGI, $A M$, 96, R. 3. Probanza de Juan Freyle (1554). AGI, $A M$, 204, N. 36. Probanza de Juan Gallego (1558). AGI, AM, 205, N. 33. Probanza de Álvaro de Zamora (1559). AGI, $A M$, 208, N. 28. Probanza de Juan de Riberol (1565). AGI, $A M, 173$, N. 61. Probanza de Francisco de Leiva (1590). AGI, $A M, 108$. Probanza de Martín de Alvear (1585). AGI, $A M$, 115. Probanza de Martín de Alvear (1595). AGI, $A M, 97$, R. 5. Probanza de Juan Gallego y de los demás intérpretes de la Audiencia de México (1567).
} 
realidad plurilingüística del continente americano, sino también el grado de autonomía del que gozaba la Audiencia en un campo tan crucial para el correcto desenvolvimiento de la justicia, así como las tensiones desatadas por la cuestión de la interpretación en el ámbito judicial en la Nueva España del siglo xvi.

\section{LOS PRIMEROS NOMBRAMIENTOS DE INTÉRPRETES \\ EN LA REAL AUDIENCIA DE MÉXICO}

La serie de nombramientos de intérpretes que se encuentran en el Archivo General de la Nación de México comienza en 1555. Sin embargo, no cabe duda de que la Audiencia recurrió a especialistas de la traducción desde su creación. En efecto, los indígenas necesitaban contratar los servicios de personas bilingües para que les asistieran en sus pleitos y, a su vez, los oidores tenían que colaborar con gente capaz de realizar traducciones para cumplir con sus funciones de gobierno y justicia. De hecho, la actividad de los intérpretes se menciona en varias cédulas tempranas en las que la corona ordenó que estos intermediarios no llevaran a los indios “joyas ni otras cosas" (1529), que se viera si convenía que concurrieran dos intérpretes en los juzgados (1530), que se informara al Consejo sobre el salario de los nahuatlatos (1533) $\mathrm{y}$, finalmente, que se permitiera que los indios se presentasen en los juicios acompañados por un "cristiano amigo" encargado de traducir sus demandas (1537). ${ }^{19}$ Apoyándose en la información

${ }^{19}$ Cédula que manda que a los que fueran intérpretes y lenguas en la Nueva España no pidan ni lleven a los indios joyas ni otras cosas so pena de destierro y pérdida de bienes, Toledo, 24 de agosto de 1529. Capítulo de la instrucción que se dio al presidente y oidores de la Audiencia de la Nueva España en 12 de julio de 1530 que manda provean lo que más convenga cerca de concurrir dos intérpretes juntos o cada uno por sí a la interpretación. Capítulo de carta que la Serenísima Emperatriz escribió a la Audiencia de México en 20 de abril de 1533 que manda enviare relación al Consejo de Indias del salario de los naguatatos. Cédula que manda que cuando la Audiencia u otras justicias enviaren a llamar algún indio que no sepa la lengua castellana para saber de él alguna cosa 
contenida en varias crónicas, Grunberg apunta en su Dictionnaire des conquistadores espagnols que Juan Pérez, cuyo interés por el náhuatl le valió el alias de Juan Pérez Malinche, sirvió como intérprete en fechas tempranas. ${ }^{20} \mathrm{El}$ conquistador Álvaro de León también desempeñó el oficio, ya que el cargo de "naguatato" aparece junto con su nombre en "la lista de los conquistadores y de sus hijos que han perdido sus encomiendas y que reciben una renta” elaborada en la década de $1540 .{ }^{21}$

No obstante, para conocer la identidad de los primeros intérpretes de la Audiencia de México, es necesario recurrir a fuentes judiciales en las que se nombra a aquellos oficiales, sea porque estuvieron encargados de traducir las declaraciones de los testigos indígenas, sea porque los visitadores trataron de evaluar si cumplieron sus funciones con honestidad. Los pleitos en los que estuvo involucrado Hernán Cortés en la década de 1530 permiten identificar a los primeros intérpretes de la Audiencia. ${ }^{22} \mathrm{Se}$ puede comprobar que Álvaro de Zamora, Pedro García, Juan de Ledesma y Andrés Díaz sirvieron este oficio en el juicio contra Nuño de Guzmán y los oidores Juan Ortiz Matienzo y Diego Delgadillo por apropiarse indebidamente del servicio y tributos de Huejotzingo. En el mismo documento, se acusa al intérprete Antonio Velázquez de que hubiera recibido gallinas, fanegas de

pueda llevar consigo un cristiano amigo, Valladolid, 12 de septiembre de 1537. Encinas, Cedulario, lib. II, f. 367-370 y lib. IV, f. 359.

${ }^{20}$ Grunberg, Dictionnaire, pp. 415-416. El autor se basa en los Anales de Tlatelolco, la Historia verdadera de Bernal Díaz del Castillo, la Crónica de Nueva España de Cervantes de Salazar, la Historia general de Herrera y la Monarquía indiana de Torquemada. También señala que hacia 1540 cambió su nombre por el de Juan Pérez Arteaga.

${ }^{21}$ Grunberg, Dictionnaire, pp. 267-268. El autor se fundamenta en la lista de los conquistadores y de sus hijos que habían perdido sus encomiendas y que recibían una renta. AGI, $M, 96$, R. 4 y en Paso y Troncoso, Epistolario, vol. 15 , doc. 872, p. 156.

${ }^{22}$ Agradezco a Rossend Rovira Morgado por haber llamado mi atención sobre la pertinencia de esta documentación para identificar a los primeros intérpretes de México. 
maíz, huevos, pescado y ropa cuando acompañó a Matienzo y Delgadillo en la visita de aquel pueblo en $1529 .{ }^{23}$ Cabe señalar que Andrés Díaz volvió a servir como nahuatlato en el pleito contra Guzmán, Matienzo y Delgadillo sobre el aprovechamiento de Tuxpan, Amula, Zapotlán y Tamazula. ${ }^{24}$ Asimismo, en 1532, Pedro de Molina fue encargado de traducir los testimonios indígenas de la información destinada a averiguar si los indios habían regalado joyas a Cortés. ${ }^{25}$ Y en 1534 Pedro García tradujo la declaración de los indios de Cuernavaca sobre el pago de tributos. ${ }^{26}$ La mayoría de aquellos oficiales fueron sometidos a juicios de residencia: Pedro García fue residenciado por Francisco de Loaysa (1535-1536) y Hernando de Tapia, Antonio Ortiz, Tomás de Rijoles y Pedro de Molina lo fueron por Tello de Sandoval (1543-1547) y por López de Montealegre (1553-1560). ${ }^{27}$

23 Pleito de Cortés contra Nuño de Guzmán y los oidores Matienzo y Delgadillo por los tributos y servicios del pueblo de Huejotzingo (1531), en Documentos cortesianos, vol. 3, pp. 209, 205, 207 y 211.

${ }^{24}$ Cabe señalar que se le acusa a Nuño de Guzmán, entre otros cargos, de que hubiera sacado de aquellos pueblos a 665 indígenas para participar en la guerra en contra de los chichimecas en la frontera norte de la Nueva España. Ahora bien, la mayoría de aquellas personas eran indios del común o macebuales, pero también destaca la presencia de 3 caciques, 46 principales y nada menos que 32 nahuatlatos. Pleito del Marqués del Valle contra Nuño de Guzmán y los oidores Matienzo y Delgadillo sobre aprovechamiento de los pueblos de Tuxpan, Amula, Zapotlán y Tamazula (1531-1533), en Documentos cortesianos, vol. 3, pp. 235 y 244-246.

${ }^{25}$ Información para averiguar si los indios de Nueva España regalaron al Marqués del Valle joyas cuando volvió de España (1532), en Documentos cortesianos, vol. 3, p. 310. Es interesante comprobar que Pedro de Molina también sirvió como intérprete en el juzgado eclesiástico, puesto que su nombre aparece en los juicios de idolatría fenecidos en la década de 1530. Entre los intérpretes figuran, asimismo, los clérigos Juan González y Diego Díaz, así como los civiles Luis de León, Alonso Mateos y el indígena Pedro. Procesos de indios, ídolatras y hechiceros pp. 18, 76, 110 y 120.

${ }^{26}$ Declaración de los tributos que los indios de Cuernavaca hacían al Marqués del Valle (1534), en Documentos cortesianos, vol. 4, pp. 11 y 14.

27 Ruiz Medrano, Reshaping New Spain, pp. 26, 163, 167, 170 y 192. 
También conviene señalar que la declaración de los indios de Cuernavaca ofrece datos interesantes sobre las técnicas de traducción utilizadas por los intérpretes de Nueva España en aquella época temprana. Permite comprobar que las traducciones eran, en muchos casos, una síntesis entre lo escrito y lo oral. En efecto, los indígenas solían aportar documentos escritos según la usanza prehispánica y leerlos -o más bien interpretarlos - en voz alta para esclarecer su contenido. ${ }^{28}$ Por consiguiente, la "traducción" del intérprete se basaba tanto en el documento pictográfico (que llamaban "pinturas") como en el testimonio oral. Las aclaraciones introductorias que brindó el intérprete Pedro García despejan cualquier duda al respecto, pues asienta que:

[...] el 24 de enero de 1534 años trujeron ocho pinturas los indios de la provincia de Guanavaquez y me las dieron a mí, Pedro García intérprete de esta Real Audiencia e me rogaron que las diese a los senores presidentes e oidores de la Real Audiencia e se las declarase de la misma manera que los dichos indios de Guanavazuez a mi e las declararon.

\section{Y, al final del documento, especifica que}

[...] la cual dicha pintura va declarada por mí, Pedro García, naguatlato e lengua de la Audiencia Real, y juro a Dios y a esta Santa Cruz que a todo mi saber e entender que las dichas pinturas así de tributos comidas e servicios e agravios como de las casas tributarias que haya en Guanavaquez y sus sujetos van bien declaradas e interpretadas como las dieron pintadas e declararon los dichos indios. ${ }^{29}$

\footnotetext{
${ }^{28}$ Sobre este tipo de documentos y el valor probatorio que tuvieron en los juzgados novohispanos, véase Ruiz Medrano y Valle, "Los colores de la justicia”.

${ }_{29}$ Declaración de los tributos que los indios de Cuernavaca hacían al Marqués del Valle (1534), en Documentos cortesianos, vol. 4, pp. 11 y 14.
} 
Si bien varios intérpretes sirvieron en la Audiencia de México desde la década de 1530, parece que no fue sino hasta la de 1550 cuando el presidente y los oidores empezaron a otorgar de manera sistemática nombramientos a estos oficiales. Es probable que esta fecha deba relacionarse con las ordenanzas que el virrey don Antonio de Mendoza promulgó en 1548 y en las que pretendió institucionalizar el cargo. Así, pues, el virrey ordenó que hubiera un número limitado de titulares en la Audiencia de México, que éstos recibiesen nombramientos y prestasen juramento, que no pudiesen recibir presentes, ni oír "en su casa a los indios", ni ordenar "peticiones a los indios", ni contratar con los indios, que asistiesen a los acuerdos, audiencias y visitas de las cárceles de indios, que recibiesen "para cada un día que salieren de la ciudad [...] un peso de oro común y no más" y que sus derechos por cada testigo se elevasen a dos tomines. ${ }^{30} \mathrm{De}$ este modo, no extraña que, en la sección "Reales Cédulas Duplicadas" del Archivo General de la Nación de México, se encuentren 17 nombramientos que la Audiencia otorgó a 13 intérpretes diferentes entre 1555 y 1606, divergencia que se explica porque algunos titulares recibieron más de un nombramiento, como fue el caso de Juan de Riberol, Juan Grande y Alonso Hernández Bocanegra (véase el cuadro 1).

Cabe señalar que esta serie no es del todo completa, ya que varios documentos indican el nombre de un predecesor cuyo nombramiento no siempre pudo localizarse. Así ocurre con Hernando de Tapia (mencionado en el nombramiento de Juan de Riberol), con Álvaro de Zamora (citado en el de Pedro López), con Francisco Osorio Ribadeo (identificado en el de Juan de Leiva en 1573) y con Diego de León (mencionado en el de Luis de León). Esta lista aún se alarga si se toma en cuenta la información contenida en las probanzas de méritos y servicios que algunos intérpretes mandaron al Consejo de Indias para

$\overline{30}$ Mendoza, Ordenanzas, f. 30v. 
Cuadro 1

NOMBRAMIENTOS DE INTÉRPRETES EN LA REAL AUDIENCIA DE MÉXICO (1555-1606)

\begin{tabular}{|c|c|c|c|}
\hline Fecha & Nombre & Lengua & Referencia \\
\hline $28 / 3 / 1555$ & Juan de Riberol & Náhuatl & $\begin{array}{l}\text { AGN, } R C D \text {, vol. } 1 \text {, } \\
\text { exp. } 68 \text {, f. } 75 \mathrm{v} .\end{array}$ \\
\hline $12 / 6 / 1555$ & Pedro de Luna & $\begin{array}{l}\text { Náhuatl/ } \\
\text { Tarasco }\end{array}$ & $\begin{array}{l}\text { AGN, } R C D \text {, vol. } 1 \text {, } \\
\text { exp. } 72 \text {, f. } 77 \mathrm{v} \text {. }\end{array}$ \\
\hline $7 / 2 / 1564$ & Juan Grande & Náhuatl & $\begin{array}{l}\text { AGN, } R C D \text {, vol. } 1 \text {, } \\
\text { exp. } 243 \text {, f. 216v. }\end{array}$ \\
\hline $3 / 12 / 1564$ & Juan de Riberol & Náhuatl & $\begin{array}{l}\text { AGN, } R C D \text {, vol. } 1 \text {, } \\
\text { exp. } 265 \text {, f. } 235 .\end{array}$ \\
\hline $8 / 2 / 1566$ & Pedro López [Barahona] & Náhuatl & $\begin{array}{l}\text { AGN, } R C D \text {, vol. } 1 \text {, } \\
\text { exp. } 294 \text {, f. } 261 .\end{array}$ \\
\hline $17 / 12 / 1573$ & Juan de Leiva & Náhuatl & $\begin{array}{l}\text { AGN, } R C D \text {, vol. } \\
47 \text {, exp. } 476 \text {, f. } 286 \mathrm{v} \text {. }\end{array}$ \\
\hline $28 / 11 / 1575$ & Juan Grande & Náhuatl & $\begin{array}{l}\text { AGN, } R C D \text {, vol. } 2 \text {, } \\
\text { exp. } 167, \text { f. } 90 .\end{array}$ \\
\hline $\mathrm{xx} / 3 / 1586$ & Pablo Pérez, indio & Otomí & $\begin{array}{l}\text { AGN, } R C D \text {, vol. } 2 \text {, } \\
\text { exp. } 177, \text { f. } 99 \mathrm{v} .\end{array}$ \\
\hline $31 / 7 / 1586$ & Luis de León & Náhuatl & $\begin{array}{l}\text { AGN, } R C D \text {, vol. } 2 \text {, } \\
\text { exp. } 192 \text {, f. } 110\end{array}$ \\
\hline $31 / 7 / 1586$ & $\begin{array}{l}\text { Alonso Hernández } \\
\text { Bocanegra }\end{array}$ & Náhuatl & $\begin{array}{l}\text { AGN, } R C D \text {, vol. 2, } \\
\text { exp. } 193 \text {, f. } 110 .\end{array}$ \\
\hline $31 / 7 / 1586$ & Alonso Solís de Aguirre & Náhuatl & $\begin{array}{l}\text { AGN, } R C D \text {, vol. } 2 \text {, } \\
\text { exp. 194, f. 110v. }\end{array}$ \\
\hline $27 / 8 / 1587$ & Bernardino de Leiva & Náhuatl & $\begin{array}{l}\text { AGN, } R C D \text {, vol. } 2 \text {, } \\
\text { exp. } 223 \text {, f. } 133 .\end{array}$ \\
\hline $15 / 9 / 1588$ & Francisco de Leiva & Náhuatl & $\begin{array}{l}\text { AGN, } R C D \text {, vol. } 2 \text {, } \\
\text { exp. } 303 \text {, f. } 164\end{array}$ \\
\hline $15 / 9 / 1588$ & Francisco Granado & Náhuatl & $\begin{array}{l}\text { AGN, } R C D \text {, vol. } 2 \text {, } \\
\text { exp. } 304 \text {, f. } 164 .\end{array}$ \\
\hline $22 / 11 / 1588$ & $\begin{array}{l}\text { Alonso Hernández } \\
\text { Bocanegra }\end{array}$ & Náhuatl & $\begin{array}{l}\text { AGN, } R C D \text {, vol. } 2 \text {, } \\
\text { exp. } 316, \text { f. } 173 .\end{array}$ \\
\hline $11 / 1 / 1589$ & Juan de Riberol & Náhuatl & $\begin{array}{l}\text { AGN, } R C D \text {, vol. } 2 \text {, } \\
\text { exp. } 373 \text {, f. } 206 .\end{array}$ \\
\hline $2 / 8 / 1606$ & Francisco de Lerria & Tarasco & $\begin{array}{l}\text { AGN, } R C D \text {, vol. } 5 \text {, } \\
\text { exp. } 141, \text { f. } 29 \mathrm{v} .\end{array}$ \\
\hline
\end{tabular}


pedir mercedes. En efecto, hemos localizado las probanzas de Juan Freyle (1554), Juan Gallego (1558), Álvaro de Zamora (1559), Juan de Riberol (1565) y Francisco de Leiva (1590), así como una probanza colectiva presentada en 1567 por Juan Gallego en su nombre y el de los intérpretes Juan de Riberol y Rodrigo Gutiérrez. ${ }^{31}$ Según estos datos, 20 titulares llegaron a desempeñar el oficio de intérprete en la Audiencia de México en la segunda mitad del siglo Xvi -Hernando de Tapia, Juan Freyle, Juan Gallego, Juan de Riberol, Álvaro de Zamora, Rodrigo Gutiérrez, Pedro de Luna, Juan Grande, Pedro López [Barahona], Francisco Osorio Ribadeo, Juan de Leiva, Pablo Pérez, Diego de León, Luis de León, Alonso Hernández Bocanegra, Alonso Solís de Aguirre, Bernardino de Leiva, Francisco Granado, Francisco de Leiva y Francisco de Lerria.

Si bien la mayoría de aquellos oficiales eran intérpretes de náhuatl, conviene señalar que Pedro de Luna fue nombrado en 1555 para traducir al castellano no solamente los negocios presentados en lengua náhuatl, sino también en tarasco, sustituido en 1606 por Francisco de Lerria. ${ }^{32}$ Por otro lado, en una provisión de 1566 la Audiencia se refirió al "alguacil e intérprete" indígena de la lengua mixteca Juan Juárez, a quien otorgó una ayuda de 30 pesos de oro común "por el cargo que tiene de la capilla y de las demás cosas de ella". ${ }^{33}$ Finalmente, el indígena

${ }^{31}$ A GI, $A M, 204$, N. 36, 25 fs. Probanzas de Juan Gallego (1551-1552 y 1558). AGI, $A M, 205$, N. 33, 24 fs. Probanzas de Álvaro de Zamora (1559 y 1570). AGI, $A M, 96$, R. 3. Probanza de Juan Freyle (1554). AGI, $A M$, 208, N. 32. Probanza de Juan de Riberol (1565). AGI, $A M, 173$, N. 61. Francisco de Leiva suplica se le dé confirmación y título del oficio que sirve de intérprete de la Real Audiencia de México (1590). AGI, AM, 97, R. 5, 6 fs. Probanza de Juan Gallego en nombre de los intérpretes de las lenguas de la Nueva España (1567). ${ }^{32}$ AGN, RCD, vol. 1, exp. 72, f. 77v. Nombramiento de Pedro de Luna (1555). AGN, $R C D$, vol. 5, exp. 141, f. 29v. Nombramiento de Francisco de Lerria (1606).

${ }^{33}$ AGN, $R C D$, vol. 1, exp. 321, f. 289v. Que se le pague a Juan Juárez, indio alguacil e intérprete de la lengua mixteca, 30 pesos de oro común por el cargo 
Pablo Pérez fue designado intérprete de la lengua otomí en $1586 .^{34}$ Esos elementos muestran que la diversidad lingüística característica de los territorios que quedaban bajo la jurisdicción de la Audiencia de México fue tomada en cuenta por los actores históricos y que el aparato administrativo de la Monarquía hispana se adaptó a esta realidad americana. No hay que olvidar, en efecto, que todos los pleitos de la región llegaban a la Audiencia en grado de apelación y que el examen de testigos que hablaran el mixteco, el otomí o el tarasco podía ser necesario en el marco de algunos pleitos. No obstante, también cabe recordar que el náhuatl sirvió como lingua franca en varias regiones de la Nueva España, en especial en los juzgados, incluso los de primera instancia. ${ }^{35}$ Eso probablemente explique el importante desfase que existe entre el número de intérpretes del náhuatl, por un lado, y del tarasco, otomí y mixteco, por otro.

Además, Pedro de Luna tenía que dividir su actividad entre la traducción del náhuatl y del tarasco, y Juan Juárez desempeñaba la actividad de alguacil, por lo que debió servir el oficio de intérprete del mixteco de forma puntual, en función de las necesidades de la Audiencia. En realidad sólo Pedro Pérez parece haber tenido la posibilidad de ejercer su cargo de intérprete del otomí de tiempo completo. De hecho, el grado de informalidad que

que tiene de la capilla y de las demás cosas de ella (1566).

${ }_{34}$ AGN, $R C D$, vol. 2, exp. 177, f. 99v. Nombramiento de Pablo Pérez, indio (1586). Cabe señalar que siguieron nombrándose intérpretes de la lengua otomí en el siglo xvir. El juzgado de indios da a Joseph Hipólito nombramiento de intérprete de los de la lengua otomí para que asista a negocios que ocurrieren en el gobierno y en la Real Audiencia (1683). AGN, I, vol. 26, cuaderno 2, f. 192v. Sobre este aspecto, véase Martínez Peñalosa, "Noble purépecha", pp. 22-24.

${ }_{35}$ Sobre el uso del náhuatl como lingua franca en la provincia de Villa Alta (Oaxaca) y en Guatemala, véanse, respectivamente, YannaKaKis, "Making Law Intelligible"; Matthew y Romero, "Náhuatl and Pipil in Colonial Guatemala". Sobre la promoción de las linguas francas por la corona española, consúltese Estenssoro e Itier, "Langues indiennes". 
implicaban estas disposiciones condujo a situaciones susceptibles de vulnerar los derechos de los hablantes de algunas lenguas autóctonas. Así, no extraña que, en marzo de 1583, el abogado Francisco de Herrera presentara ante los oidores una petición en la que denunciaba que el hijo del receptor de la Audiencia, Sebastián Vázquez Terrazas, había realizado trabajos de interpretación para los indios de Atuyaquillo "sin saber la lengua mixteca ni entenderla y para disimularlo se mudó el nombre [...] y se nombró Sebastián Caro" ${ }^{36}$ Pero lo más sorprendente es que, en este caso de usurpación de tierras, Francisco de Herrera defendía a la parte adversa, por lo que añadió que los indios dieron a Sebastián Vázquez Terrazas y a su padre "140 pesos de oro común por efecto de tenerlos favorables". ${ }^{37}$ En otras palabras, los vecinos de Atuyaquillo sabían que el hijo del receptor no hablaba ni entendía su lengua, pero pretendieron asegurarse una "traducción" de los hechos que fuese favorable a sus intereses. En cualquier caso, la ausencia de un intérprete oficial de la lengua mixteca en la Audiencia de México estaba complicando el procedimiento legal.

Como ya se ha dicho, la situación era muy diferente para el náhuatl, puesto que varios intérpretes trabajaban simultáneamente en la Audiencia para tratar el importante volumen de negocios que se ventilaban en esta lengua. ${ }^{38} \mathrm{El}$ hecho de que

${ }^{36}$ AGN, IV, 6611, exp. 30. Petición de Francisco de Herrera en nombre de Mathias Vázquez para que no se acepte la interpretación que hizo Sebastián Vázquez a los indios del pueblo de Atuyaquillo, por no conocer la lengua mixteca, en el pleito que tiene por tierras el dicho Mathias Vázquez con María Xirón y los indios de dicho pueblo (1583).

${ }^{37}$ AGN, $I V, 6611$, exp. 30. Las cursivas son mías.

${ }_{38}$ A este propósito cabe recordar, en efecto, que en 1530 la corona había alentado que fueran dos los intérpretes que servían en los juzgados americanos para limitar el riesgo de traducciones fraudulentas. Capítulo de instrucción que se dio al presidente y oidores de la Audiencia de la Nueva España en 12 de julio de 1530 que manda provean lo que más convenga acerca de concurrir dos intérpretes juntos o cada uno por sí a la interpretación. Encinas, Cedulario, 
Juan Gallego, Juan de Riberol y Rodrigo Gutiérrez presentasen una probanza colectiva en 1567 confirma esta hipótesis. ${ }^{39}$ Por otro lado, Juan Grande, Pedro López y Juan de Leiva recibieron nombramientos en fechas muy cercanas y, en 1586, la suspensión simultánea de Diego de León, Juan de Leiva y Juan de Riberol, debido a la visita del arzobispo Pedro Moya de Contreras, dio lugar a tres nuevas designaciones. ${ }^{40}$ Siendo aquellos nombramientos provisionales, en 1587 Alonso Hernández Bocanegra fue sustituido por Bernardino de Leiva y, al año siguiente, Francisco de Leiva y Francisco Granado reemplazaron a Luis de León y a Alonso de Solís Aguirre. ${ }^{41}$ Pero el repentino fallecimiento de Granado obligó a la Audiencia a volver a nombrar a Alonso Hernández Bocanegra en su lugar. ${ }^{42}$ De este modo, en 1588 la Audiencia de México de nuevo contaba con tres titulares - Francisco de Leiva, Bernardino de Leiva y Alonso Hernández Bocanegra- y hasta con cuatro cuando Juan de Riberol fue restituido en su cargo en 1589. Finalmente,

lib. 2, f. 367. El gobernador de Yucatán también contó con dos intérpretes de la lengua maya al menos desde 1560. Cunill, "Los intérpretes de Yucatán”.

${ }^{39}$ AGI, $A M, 97$, R. 5, 7 fs. Probanza de Juan Gallego y de los intérpretes de las lenguas de Nueva España (1567).

${ }^{40}$ La visita del arzobispo Pedro Moya de Contreras, en efecto, se menciona como causa de la suspensión de los mencionados titulares en los nombramientos de sus sucesores. AGN, RCD, vol. 2, exp. 192, f. 110. Nombramiento de intérprete a Luis de León (1586). AGN, RCD, vol. 2 exp. 193, f. 110. Nombramiento de intérprete a Luis Bocanegra (1586). AGN, RCD, vol. 2, exp. 194, f. 110v. Nombramiento de intérprete a Alonso Solís Aguirre (1586). Sobre esta visita, véase Poole, Pedro Moya de Contreras. Los documentos originales, por su lado, se encuentran en AGI, E, 271A. Visita de la Audiencia de México y demás tribunales por Pedro de Moya y Contreras, arzobispo de México (1584). ${ }^{41}$ AGN, $R C D$, vol. 2, exp. 223, f. 133. Nombramiento de intérprete a Bernardino de Leiva (1587). AGN, RDC, vol. 2, exp. 303, f. 164. Nombramiento de intérprete a Francisco de Leiva (1588). AGN, RDC, vol. 2, exp. 304, f. 164. Nombramiento de intérprete a Francisco Granado (1588).

42 AGN, $R C D$, vol. 2, exp. 316, f. 173. Nombramiento a Alonso Hernández Bocanegra (1588). 
en una carta de 1592 el virrey Velasco la explicaba al rey Felipe II que, en aquellas fechas, estaban sirviendo cuatro intérpretes en la Audiencia de México —Francisco de Leiva, Juan Méndez, Juan de Riberol y Pedro López Barahona. ${ }^{43}$

\section{CRONOLOGÍA DE LA OCUPACIÓN DEL CARGO \\ DE INTÉRPRETE DE LA AUDIENCIA DE MÉXICO}

La información recogida permite identificar a dos generaciones de intérpretes. En la primera mitad del siglo xvi destacan los nahuatlatos Antonio Velázquez, Juan de Ledesma, Andrés Díaz, Pedro de Molina, Pedro García, Hernando de Tapia, Antonio Ortiz, Tomás de Rijoles, Juan Pérez Arteaga y Álvaro de León (cuadro 2). La mayoría de aquellos titulares, que habían llegado a América en los primeros años de la conquista, fallecieron entre 1550 y $1560 .{ }^{44} \mathrm{El}$ intérprete indígena Hernando de Tapia murió en 1555. ${ }^{45}$ También se puede argüir que Álvaro de Zamora, Juan Gallego y Juan Freyle fueron figuras de transición, a caballo entre la primera y la segunda mitad del siglo xvi. El primero empezó a prestar sus servicios en 1534, puesto que uno de los testigos presentados en su probanza de 1559 declaró que hacía “'más de 25 años que vio que como tal intérprete hacía negocios ante el licenciado Salmerón que a la sazón presidía en esta dicha Audiencia”. ${ }^{46}$

${ }^{43}$ AGI, $A M, 22$, N. 96bis, 2 fs. El virrey don Luis de Velasco a Su Majestad: Relación de los oficiales de la Real Audiencia de México, 2 de junio de 1592.

${ }_{44}$ Según Grunberg, Tomás Rijoles murió en 1547, Álvaro de León en 1554, Juan Pérez en 1558, Antonio Velázquez en 1560, Juan de Ledesma en 1561. Grunberg, Dictionnaire, pp. 265, 268, 415, 442 y 569.

45 El fallecimiento de Hernando de Tapia se menciona como motivo del nombramiento de Juan de Riberol fechado el 28 de marzo de 1555. AGN, RCD, vol. 1, exp. 68, f. 75v. Este dato coincide con las informaciones encontradas por Rovira Morgado, que también sitúa el fallecimiento del intérprete indígena en aquel año. Rovira Morgado, San Francisco Padremeh, p. 105.

46 AGI, $A M, 205$, N. 33, f. 3. Testimonio de Francisco Verdugo en la probanza de Álvaro de Zamora (1559). 
Cuadro 2

PRIMERA GENERACIÓN DE INTÉRPRETES DE LA AUDIENCIA

DE MÉXICO

\begin{tabular}{ll}
\hline \multicolumn{1}{c}{ Fecha } & Nombre del intérprete \\
\hline ca. $1530-$ ca. 1560 & Antonio Velázquez \\
ca. $1530-\mathrm{xxx}$ & Pedro García \\
ca. $1530-$ ca. 1561 & Juan de Ledesma \\
ca. $1530-\mathrm{xxx}$ & Andrés Díaz \\
ca. $1540-\mathrm{xxx}$ & Pedro de Molina \\
ca. $1540-1558$ & Juan Pérez de Arteaga \\
ca. $1540-$-ca.1554 & Álvaro de León \\
ca. $1540-\mathrm{xxx}$ & Antonio Ortiz \\
ca. $1540-1547$ & Tomás de Rijoles \\
ca. $1540-1555$ & Hernando de Tapia \\
1534-1566 & Álvaro de Zamora \\
1542-ca. 1570 & Juan Gallego \\
1545-ca. 1554 & Juan Freyle \\
\hline
\end{tabular}

Debió de fallecer en 1566, fecha en la que se estipuló que Pedro López Barahona lo sustituiría en el cargo. ${ }^{47}$ Juan Gallego, por su lado, declaró en su probanza que fue intérprete desde 1542 y que, a partir de 1554, también asumió otras funciones, como la de juez de comisión. ${ }^{48}$ Este titular siguió ejerciendo el cargo por lo menos hasta 1570, puesto que en 1563 y 1567 presentó peticiones en su nombre y en el de "los demás intérpretes" de la Audiencia de México y también está identificado como intérprete en un documento de $1570 .{ }^{49}$ Finalmente, Juan Freyle comenzó a prestar sus servicios de intérprete en 1545 y siguió ocupando

${ }_{47}$ AGN, RCD, vol. 1, exp. 294, f. 261. Nombramiento de Pedro López Barahona (1566).

${ }^{48}$ AGI, $A M, 204$, N. 36, 25 fs. Probanza de Juan Gallego (1558).

${ }^{49}$ AGI, $A M, 97$, R. 5, 7 fs. Probanza de Juan Gallego y de los intérpretes de las lenguas de Nueva España (1567). AGN, RDC, vol. 47, exp. 188, f. 101v. Fianza para escribano real que se dio a Juan Gallego, intérprete de la Audiencia de México, en favor de Miguel de Zaragoza (1570). 
el cargo hasta por lo menos 1554, año en el que menciona esta actividad en su probanza de méritos y servicios. ${ }^{50}$

En cambio, Francisco de Osorio Ribadeo, Juan de Riberol, Pedro López de Barahona, Juan Grande y Juan de Leiva aparecen como figuras centrales de la interpretación en la segunda mitad del siglo xvi (véase el cuadro 3). El primero debió empezar a ejercer sus funciones hacia 1554, fecha en la que recibió una renta de 200 pesos, y no dejaría el oficio sino hasta su muerte en $1573 . .^{51}$ Por otro lado, los dos nombramientos de Juan de Riberol permiten afirmar que este titular ocupó el oficio de 1555 a 1586, cuando fue suspendido debido al juicio de residencia que estaba realizando el arzobispo Pedro Moya de Contreras. ${ }^{52}$ Pero esta suspensión fue de corta duración, ya que Juan de Riberol fue restituido en sus funciones en 1589 . No sorprende, por lo tanto, que su nombre aparezca en la lista de los intérpretes de la Audiencia realizada por el virrey don Luis de Velasco en $1592 .{ }^{53}$ Este documento también permite establecer

${ }^{50}$ AGI, $A M, 96$, R. 3. Probanza de Juan Freyle (1554). Cabe señalar que Freyle aparece como intérprete en un juicio de 1550. AGN, $I V$, vol. 2374, exp. 9. Presentación de testigos hecha por Francisco de Llania por medio del intérprete Juan Freyle (1550).

${ }^{51}$ Grunberg, Dictionnaire, p. 444. Apoyándose en la relación de rentas de indios vacos señaladas a los conquistadores de Nueva España (AGI, $P R, 20$, N. 5, R. 15), el autor afirma que Francisco de Ribadeo empezó a cobrar una renta de 200 pesos a partir de 1554. Es probable que esta renta correspondiese a su salario como intérprete de la Audiencia de México. En el nombramiento de Juan de Leiva se explica que este nuevo titular iba a sustituir a Francisco de Osorio Ribadeo, que acababa de fallecer. AGN, $R C D$, vol. 47, exp. 476, f. 286v. Nombramiento de intérprete a Juan de Leiva (1573).

${ }^{52}$ AGN, $R C D$, vol. 1, exp. 68, f. 75v. Nombramiento de intérprete a Juan de Riberol (1555). AGN, RCD, vol. 2, exp. 194, f. 110v. Nombrando intérprete a Alonso Solís Aguirre (1586). AGI, AM, 208, N. 32. Probanza de Juan de Riberol (1565). AGI, $A M, 208$, N. 32.

53 AGN, $R C D$, vol. 2, exp. 373, f. 206. Nombramiento a Juan de Riberol (1589). AGI, $A M, 22$, N. 96bis, 2 fs. El virrey don Luis de Velasco a Su Majestad (1592). 
que Pedro López de Barahona, nombrado en 1566, seguía ejerciendo el oficio en aquella fecha. ${ }^{54} \mathrm{Juan}$ Grande, que había sido nombrado por primera vez en 1564, ejercía como intérprete de la Real Hacienda en 1591 y acabó siendo solicitador de los naturales a principios del siglo xvI. ${ }^{55}$ Finalmente, Juan de Leiva, que recibió su nombramiento en 1573, fue suspendido de su cargo en 1586, debido a la visita de Pedro Moya de Contreras, $\mathrm{y}$ no fue reintegrado en sus funciones posteriormente, puesto que falleció al año siguiente. ${ }^{56}$

Cabe señalar que la década de 1580 estuvo marcada por cierta inestabilidad, ya que se multiplicaron los nombramientos provisionales, no sólo en razón de las suspensiones provocadas por el juicio de residencia del arzobispo Pedro Moya de Contreras, sino también a causa del fallecimiento de varios titulares. En estas circunstancias, la transmisión del oficio entre padres e hijos parece haber sido considerada como una opción satisfactoria, al menos de manera interina. Así, pues, en 1586 Luis de León fue nombrado para sustituir a su padre Diego de León, suspendido por Moya de Contreras. Sin embargo, tan sólo dos años después Luis de León tuvo que abandonar el cargo en favor de Francisco de Leiva, quien lo ocuparía hasta al menos $1610 .{ }^{57}$ La suerte de

${ }^{54}$ AGI, $A M, 22$, N. 96bis, 2 fs.

${ }^{55}$ AGN, $I$, vol. 5, exp. 951, f. 315. Orden al corregidor de Xochimilco para que, en presencia de Juan Grande, intérprete de la Real Hacienda, compela a un señor Carriedo, español, a exhibir los pesos de oro y bienes que tiene en su poder pertenecientes a María Magdalena, india. Aztlhuacan (1591). AGN, IV, c. 3456, exp. 47. Juan Grande, en nombre de los naturales de Culhuacan, el gobernador, alcaldes y demás principales de este pueblo, solicita al virrey un mandamiento para que Alonso López, español, no esté en esta localidad porque los molesta y los trata de perros y dice palabras feas (1607). AGN, $I V$, c. 4259, exp. 8. Solicitud que hace Juan Grande, solicitador general de los indios, para que se investigue al español que hace negocios de indios (1605).

${ }^{56}$ AGN, $R C D$, vol. 47, exp. 476, f. 286v. Nombramiento de intérprete a Juan de Leiva (1573).

${ }^{57}$ AGN, RDC, vol. 2, exp. 192, f. 110. Nombramiento de intérprete a Luis de León (1586). AGN, $I V$, c. 1061, exp. 7, 1 f. Nombramiento de intérprete a 
Bernardino de Leiva, en cambio, fue bastante diferente, puesto que recuperó el puesto dejado por la muerte de su padre Juan de Leiva y lo ocupó hasta su fallecimiento en 1624, momento en que fue sustituido por Andrés de Mejía. ${ }^{8}$ Por consiguiente, Alonso Hernández de Bocanegra, que había reemplazado a Juan de Leiva en 1586, tuvo que abandonar el cargo en 1587. No obstante, lo recuperó en 1588, cuando falleció Francisco Granado, que acababa de ser nombrado para sustituir a Alonso Solís de Aguirre. ${ }^{59}$

También es interesante hacer notar que, en algunos casos, el relevo en el cargo se debió a una promoción social, como ocurrió con Juan Grande, que estaba prestando sus servicios en la Real Hacienda hacia 1591 y que llegó a ser solicitador de indios poco después. Esto sugiere que el oficio de intérprete fue lo suficientemente prestigioso para servir de eslabón en una carrera administrativa. Es probable, además, que la experiencia que los titulares acumulaban en los negocios indígenas fuese determinante en el momento de confiarles cargos de jueces o de defensores de indios. De hecho, si bien la corona española se esforzó por separar las actividades de interpretación de las de representante legal, en muchas ocasiones los intérpretes

Francisco de Leiva (1588). AGN, RCD, vol. 2, exp. 303, f. 164. Francisco de Leyva, intérprete de la Real Audiencia, en nombre de los indios de la parte de Santiago Tlatelolco (1610).

${ }^{58}$ AGN, RDC, vol. 2, exp. 223, f. 133. Nombramiento de intérprete a Bernardino de Leiva (1587). AGN, $R C D$, vol. 8, exp. 250, f. 317v. y exp. 254, f. 322v. Nombramiento de intérprete a Andrés de Mejía, 22 de abril de 1624 y nombramiento de intérprete a Pedro de Paz en lugar de Andrés de Mejía, 11 de julio de 1624.

${ }^{59}$ AGN, $R C D$, vol. 2 exp. 193, f. 110. Nombramiento de intérprete a Hernández Bocanegra (1586). AGN, RCD, vol. 2, exp. 316, f. 173. Nombramiento de intérprete a Alonso Hernández Bocanegra (1588). AGN, RCD, vol. 2, exp. 194, f. 110v. Nombramiento de intérprete a Alonso Solís Aguirre (1586). AGN, $R C D$, vol. 2, exp. 304, f. 164. Nombramiento de intérprete a Francisco Granado (1588). AGN, $R C D$, vol. 2, exp. 304, f. 164. 
Cuadro 3

SEGUNDA GENERACIÓN DE INTÉRPRETES

DE LA AUDIENCIA DE MÉXICO

\begin{tabular}{ll}
\hline \multicolumn{1}{c}{ Fecha } & \multicolumn{1}{c}{ Nombre del intérprete } \\
\hline 1555-1586 y 1589-ca.1592 & Juan de Riberol \\
1555-xxx & Pedro de Luna (tarasco y náhuatl) \\
1566-xxx & Juan Juárez (mixteco) \\
ca.1554-1573 & Francisco de Osorio Ribadeo \\
1564- ca.1590 & Juan Grande \\
1566- ca.1592 & Pedro López Barahona \\
ca. 1567 & Rodrigo Gutiérrez \\
$1573-1586$ & Juan de Leiva \\
xxx-1586 & Diego de León \\
$1586-$ xxx & Pablo Pérez (otomí) \\
$1586-1588$ & Luis de León \\
$1586-1588$ & Alonso Solís de Aguirre \\
$1586-1587$ y $1588-x x x$ & Alonso Hernández Bocanegra \\
$1587-1624$ & Bernardino de Leiva \\
sept.-nov. 1588 & Francisco Granado \\
$1588-$ ca.1610 & Francisco de Leiva \\
ca.1592 & Juan Méndez de Sotomayor \\
$1606-x x x$ & Francisco de Lerria (tarasco) \\
\hline
\end{tabular}

brindaron asesoramiento jurídico a sus clientes indígenas. ${ }^{60} \mathrm{El}$ caso de Juan Grande muestra, asimismo, que no sólo la Audiencia de México contaba con intérpretes, sino también otras instituciones novohispanas, como la Real Hacienda, el Tribunal de la Santa Cruzada y el juzgado del corregidor de México. Así, pues, Manuel Mancio Moctezuma fue intérprete del Tribunal de la Santa Cruzada en el siglo xvir. ${ }^{61}$ Por otro lado, Martín de Alvear sirvió como intérprete en la audiencia ordinaria, esto es, en el

${ }^{60}$ Cunill, "Justicia e interpretación”, p. 26.

${ }^{61}$ AGN, IV, vol. 2414, exp. 25. Manuel Mancio Moctezuma intérprete del Real Apostólico Tribunal de la Santa Cruzada (s. f.). 
juzgado del corregidor de México, durante el último tercio del siglo Xvi. En 1585 declaró que había sido nombrado intérprete por el corregidor Lorenzo Sánchez de Obregón en 1574. ${ }^{62}$ Y en 1595 afirmó que desempeñó estas funciones durante 15 años y aportó como pruebas dos nombramientos. El primero, fechado en 1588, le fue otorgado por el virrey Álvaro Manrique de Zúñiga para sustituir a Francisco Granado, que iba a ser intérprete de la Real Audiencia; y el segundo, fechado en 1590, le fue concedido por el virrey Luis de Velasco para reemplazar a Juan de León, que acababa de fallecer. ${ }^{63}$ Esta información pone de manifiesto la movilidad de algunos nahuatlatos que circularon entre distintas instituciones virreinales, como fue el caso de Juan Grande y de Francisco Granado (véase el cuadro 4).

\section{Cuadro 4}

INTÉRPRETES DEL CORREGIDOR Y DE LOS ALCALDES

ORDINARIOS DE LA CIUDAD DE MÉXICO (1574-1595)

\begin{tabular}{ll}
\hline \multicolumn{1}{c}{ Fecha } & \multicolumn{1}{c}{ Nombre } \\
\hline ca. 1574- ca. 1586 & Martín de Alvear \\
ca. 1586- sept.1588 & Francisco Granado \\
sept.1588-1589 & Martín de Alvear \\
1589-mayo 1590 & Juan de León \\
mayo 1590-ca. 1595 & Martín de Alvear \\
\hline
\end{tabular}

${ }^{62}$ AGI, $A M, 108$, R. 1, 24 fs. Martín de Alvear sobre que se le dé título de intérprete de México con el salario conveniente (1585). Este documento contiene el traslado de una probanza de 1580. AGI, $A M, 115, \mathrm{R} .1$.

${ }^{63}$ A GI, $A M, 115$, R.1, f. 2. Probanza de Martín de Alvear, intérprete de la lengua mexicana en la Audiencia del corregidor y alcaldes ordinarios de la ciudad de México (1595). Este documento contiene el nombramiento de intérprete de la audiencia ordinaria otorgado a Martín de Alvear, en lugar de Francisco Granado, por el virrey don Álvaro Manrique de Zúñiga, México, 19 de septiembre de 1588; y el nombramiento de intérprete de la audiencia ordinaria otorgado a Martín de Alvear, en lugar de Juan de León, por el virrey don Luis de Velasco el Joven, México, 16 de mayo de 1590. 


\section{PERFIL Y SALARIO DE LOS INTÉRPRETES}

DE LA AUDIENCIA DE MÉXICO

Ahora bien, ¿cuál era el perfil social e identidad étnica de los titulares del oficio? ¿Y en qué condiciones llegaron a ser bilingües? Como lo ha demostrado Carrasco, varios intérpretes de la Audiencia de México fueron antiguos conquistadores españoles casados con mujeres indígenas. En esta categoría el investigador incluye a Juan Pérez de Arteaga, casado con Angelina Pérez; a Antonio Ortiz, casado con doña Isabel, hija de un principal de Tlaxcala; a Juan Freyle, casado con doña Cecilia, hija de don Pedro, antiguo gobernador de Texcoco; y a Juan Grande, casado con doña Francisca Verdugo Ixtlilxóchitl. ${ }^{64}$ A esta lista hay que añadir al conquistador Âlvaro de León, que llegó a México hacia 1525 y se casó con una mujer indígena llamada Catalina. ${ }^{65}$ Pero también llama la atención el itinerario vital de Antonio Velázquez, Tomás de Rijoles, Álvaro de Zamora y Juan Gallego quienes, a diferencia de los precedentes, no aprendieron el náhuatl por mediación de sus esposas indígenas. En su caso, la juventud debió constituir un factor propicio al aprendizaje del nuevo idioma, sobre todo en el contexto de pluralidad

${ }^{64}$ Carrasco, “Indian-Spanish Marriages”, pp. 86-100 y Grunberg, Dictionnaire, pp. 170, 415-416. En su probanza Freyle declaró que su esposa, doña Cecilia, era la hija de don Pedro Tetlabuevetzquitl y de doña María Durán. Señaló, asimismo, que don Pedro era el hijo de Necaval Piltzintli, cacique y señor de la provincia en tiempos prehispánicos. Los testigos presentados para comprobar la genealogía de doña Cecilia fueron don Hernando Pimentel, don Lorenzo de Luna Zamora y don Pablo (tío de doña Cecilia), señores y principales de Tezcoco. AGI, $A M$, 96, R. 3, ff. 14r-v.-16r. Probanza de Juan Freyle (1554).

${ }^{65}$ Grunberg, Dictionnaire, pp. 267-268. Grunberg explica que la identidad indígena de Catalina está mencionada en la probanza que realizó su hijo Alonso de León en 1585. AGI, PR, 78B, N. 2, R. 7, 82 fs. También recurre a la lista de los conquistadores y de sus hijos que han perdido sus encomiendas y que reciben una renta. AGI, $A M, 96$, R. 4 y Paso y Troncoso, Epistolario, vol. 15 , doc. 872, p. 156. 
lingüística que ofrecía la ciudad de México en el siglo xvi. Según Grunberg, Antonio Velázquez “el chico” llegó a América con su tío Narváez en 1517 y Tomás de Rijoles, que llegaría en las mismas fechas, ya se dedicaba a aprender el náhuatl al tiempo de la segunda entrada a México. ${ }^{66}$ También es probable que Juan Pérez fuese bilingüe antes de casarse con su esposa indígena, puesto que varias crónicas mencionan que este joven conquistador acompañaba a doña Marina y Jerónimo de Aguilar en todos sus negocios con el fin de aprender el náhuatl..$^{67}$ Un parecer de la Audiencia de México refiere, asimismo, que el intérprete Álvaro de Zamora era "de poca edad [cuando] se halló en la conquista y toma de esta ciudad [de México] con su padre y un hermano suyo". ${ }^{68}$ Juan Gallego, por su parte, declaró en 1550 que podría

[...] haber 34 años que pasó a la Nueva España y en el dicho tiempo ha servido a Vuestra Alteza yendo en compañía del Marqués del Valle a la conquista y pacificación de la provincia de Higueras y después de conquistada se halló con Antón de Laycedo en la conquista de la provincia de Motín y después de lo susodicho fue en compañía de Nuño de Guzmán al descubrimiento, conquista y pacificación del Nuevo Reino de Galicia. ${ }^{69}$

Puesto que Juan Gallego seguía ejerciendo el oficio de intérprete en la Audiencia de México en 1570, debió ser muy joven cuando llegó a esta tierra.

Dentro de la segunda generación de intérpretes destaca la presencia de un elevado número de mestizos que, por lo general, eran hijos o nietos de un antiguo conquistador casado con una mujer indígena. No obstante, cabe señalar que esta categoría

${ }^{66}$ Grunberg, Dictionnaire, pp. 442 y 569-570.

${ }^{67}$ Grunberg, Dictionnaire, pp. 415-416.

${ }^{68}$ AGI, $A M, 205$, N. 33, f. 14. Parecer de la Audiencia de México (ca. 1560), en la probanza de Álvaro de Zamora.

69 AGI, $A M, 204$, N. 36. Probanza de Juan Gallego (1558). 
étnica no se menciona en ninguno de los nombramientos otorgados por la Audiencia y muy pocas veces en las probanzas de los titulares, documentos en los que tienden a insistir en los méritos de sus padres y a ocultar la identidad de sus madres. En 1584 Juan de Leiva explicaba, por ejemplo, que era hijo del conquistador Cristóbal Martín de Leiva y de Leonor Cansino, y nieto, a su vez, del conquistador Cristóbal Martín de Huelva. ${ }^{70}$ Pero el peticionario ocultó el matrimonio que su abuelo paterno contrajo con Catalina Martín, madre indígena de Cristóbal Martín de Leiva. ${ }^{71}$ Alonso Solís de Aguirre fue sin duda el hijo mestizo del conquistador Francisco Solís, cuya descendencia mestiza está explícitamente mencionada en el Memorial de los conquistadores de finales del siglo Xvi. ${ }^{72} \mathrm{El} \mathrm{mismo} \mathrm{documento}$ se refiere a los hijos mestizos que tuvo el conquistador Francisco Granado, por lo que el intérprete homólogo nombrado en 1588 bien pudo ser uno de ellos. ${ }^{73}$ Juan de León fue probablemente el hijo de Álvaro de León y de su esposa indígena Catalina de León, de la que tuvo seis hijos, de los cuales cinco -Gregorio, Francisco, Alonso, Angelina y Juan- recibían una renta de 50 pesos en $1554 .^{74}$ Según Carrasco, Pedro López de Barahona y Rodrigo Gutiérrez también eran mestizos. ${ }^{75}$ De hecho, el segundo pudo haber sido hijo del conquistador Francisco Gutiérrez,

70 AGI, $P R, 78 \mathrm{~B}$, N. 14, 63 fs. Información de méritos y servicios de Cristóbal Martin de Leiva, uno de los primeros conquistadores de Nueva España y particularmente de Tepeaca, a petición de su hijo Juan de Leiva (1584).

${ }^{71}$ Grunberg, Dictionnaire, p. 314.

72 Grunberg, Dictionnaire, p. 515. El autor cita el "Memorial de los conquistadores de esta Nueva España que se hallaron presentes en la toma de México", documento de finales del siglo xvi, que fue insertado en la obra de Dorantes DE Carranza, Sumaria relación, p. 448.

${ }^{73}$ Grunberg, Dictionnaire, pp. 217-218. El intérprete Francisco Granado no pudo ser la misma persona que el conquistador Francisco Granado, puesto que éste no sabía escribir y murió hacia 1570.

${ }^{74}$ Grunberg, Dictionnaire, pp. 267-268.

${ }^{75}$ Carrasco, "Indian-Spanish Marriages", pp. 87-104. El autor se apoya en la siguiente fuente: AGN, $H J$, exp. 290, f. 1476v. 
que llegó a América en 1517 y se casó hacia 1542 (en segundo matrimonio) con una mujer indígena. ${ }^{76}$ En cuanto a Pedro López de Barahona, se presentó en una petición de 1580 como descendiente de un conquistador español, pero en este documento no se refirió a la identidad de su madre. ${ }^{77}$

Si bien Francisco de Osorio Ribadeo y Juan Méndez de Sotomayor no eran mestizos, al igual que los titulares mencionados descendían de conquistadores. El primero era hijo de Francisco de Ribadeo y de Leonor de Osorio y el segundo de Hernán Méndez de Sotomayor y de la hija del conquistador Hernán Gutiérrez de Gibaja. ${ }^{78}$ El perfil de Juan de Riberol, en cambio, difiere notablemente del de los intérpretes precedentes, ya que ni era mestizo, ni era hijo de conquistador, sino que descendía de uno de los primeros pobladores de México. Su padre, Vicencio de Riberol, había sido defensor de pobres durante casi 30 años, en los cuales hizo "muy buenas obras a los indios", dándoles limosna, sacándolos de la cárcel, teniendo "en su casa enfermería y hospital de indios pobres" y enterrándolos a su costa. ${ }^{79}$ Según los testigos, Vicencio también sirvió "en los tianguis y mercados de esta ciudad por alguacil amparando a los naturales para que no se les hiciese agravio ninguno". ${ }^{80}$ Así, queda claro que Juan de Riberol estuvo en contacto con el náhuatl desde su

${ }^{76}$ Grunberg, Dictionnaire, p. 226.

77 AGN, IV, 6718, exp. 15. Pedro López Barahona, hijo de conquistador e intérprete de la Real Audiencia suplica a Vuestra Excelencia sea servido de una merced de un tenientazgo de costa (1580).

${ }^{78}$ Grunberg, Dictionnaire, pp. 327 y 444.

79 AGI, $A M, 208$, N. 32. Según Juan de Alvarado, Vicencio de Riberol ocupó el oficio de defensor de pobres durante 30 años. También sabemos que en 1559 la Audiencia permitió que Juan de Riberol heredera uno de los empleos que tenía su padre, por lo que se puede inferir que éste acababa de morir. AGN, $R D C$, vol. 1, exp. 269, f. 239. Concediendo a Juan de Riberol el empleo que tenía su padre, de llevar la cruz que acompañaba a los ajusticiados con el sueldo de cien pesos (1559). La combinación de ambos datos sugiere que Vicencio de Riberol fue abogado de pobres en la Audiencia entre 1529 y 1559.

${ }^{80}$ AGI, $A M, 208$, N. 32, fs. 3-4. Testimonios de Francisco Muñoz (1565). 
más tierna edad, lo que debió favorecer su aprendizaje de esta lengua. Muestra, asimismo, la existencia de cierta continuidad entre la representación legal de los indios y la interpretación de sus demandas y declaraciones en los juzgados, continuidad que en este caso está personificada en la relación padre/hijo. De hecho, el interrogatorio que Juan Gallego presentó en su probanza pone de manifiesto la tenue frontera que existía entre el oficio de juez y el de intérprete, debido a la naturaleza política de las actividades de traducción. Así pues, el peticionario explicaba que "en todo lo que le fue cometido, así yendo por juez como con jueces por intérprete por mandado y comisión de esta Real Audiencia, dio muy buena cuenta". ${ }^{81}$ Añadió que fue intérprete y juez tanto en la Audiencia como "fuera de ella en ir a contar pueblos y a mojonar términos y averiguar debates y diferencias entre los naturales y en otros muchos negocios" ${ }^{82}$

En resumidas cuentas, los titulares del oficio de intérprete de la Audiencia de México fueron indígenas (Hernando de Tapia, Juan Juárez y Pablo Pérez); conquistadores españoles casados con mujeres indígenas (Juan Pérez de Arteaga, Antonio Ortiz, Juan Freyle, Juan Grande y Álvaro de León); conquistadores que llegaron probablemente muy jóvenes a la Nueva España (Antonio Velázquez, Tomás de Rijoles, Álvaro de Zamora y Juan Gallego); mestizos, hijos de antiguos conquistadores y de madres indígenas (Pedro López de Barahona, Alonso Solís de Aguirre, Francisco Granado y Juan de León) o nietos y bisnietos de un conquistador español y de una mujer indígena (Juan de Leiva y Bernardino de Leiva); y criollos de padres españoles (Francisco de Osorio Ribadeo, Juan Méndez de Sotomayor y Juan de Riberol). Por lo tanto, aunque permanece la incógnita acerca de la identidad de algunos intérpretes de la Audiencia de

${ }^{81}$ AGI, $A M, 204$, N. 36, f. 9. Probanza de Juan Gallego (1558). Las cursivas son mías.

${ }^{82}$ AGI, $A M, 204$, N. 36, f. 9. Probanza de Juan Gallego (1558). 
México, se puede argüir que existió una indudable diversidad étnica entre los titulares del oficio en el siglo xvi. Guardando las proporciones, esta repartición se asemeja a la que se encuentra entre los intérpretes de la gobernación de Yucatán, donde este grupo estuvo conformado por un maya (Gaspar Antonio Chi), un hijo de conquistador español que llegó a la península de niño (Alonso de Arévalo), dos mestizos (Diego de Vargas y Antonio Nieto) y un criollo de padres españoles (Diego de Moras). ${ }^{83}$

\section{Gráfica 1}

REPARTICIÓN DE LOS INTÉRPRETES

DE LA AUDIENCIA DE MÉXICO

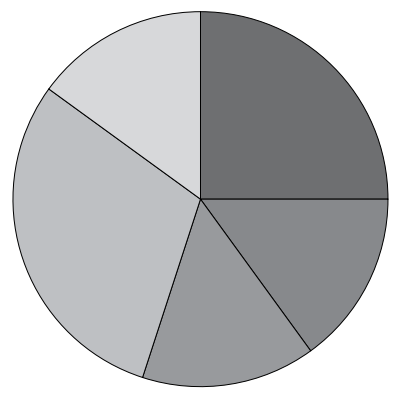

$\square$ Conquistadores casados con indígenas

$\square$ Conquistadores que llegaron jóvenes

Indígenas

Mestizos

Criollos

También es de señalar que, en la Audiencia de México, los antiguos conquistadores y su progenitura establecieron un auténtico monopolio sobre el cargo de intérprete, ya que esta categoría representa a 18 de los 22 titulares cuya identidad étnica y origen social pudieron confirmarse. ${ }^{84}$ Esta característica puede explicarse a la luz de la orden de recompensar con oficios a los

${ }^{83}$ Cunill, "Los intérpretes de Yucatán”, pp. 374-375.

${ }^{84}$ Es posible que esta situación tuviera un impacto negativo sobre la defensa de la población indígena, puesto que los intereses de ésta eran, por lo general, opuestos a los de la oligarquía novohispana. Otra investigación, centrada en la actuación de los intérpretes que sirvieron en la Audiencia, podría brindar elementos sobre esta compleja cuestión. 
conquistadores que no tenían encomienda o que la perdieron. ${ }^{85}$ Por otro lado, la dimensión generacional es relevante en el análisis, puesto que la primera generación de intérpretes estuvo conformada por conquistadores españoles, mientras que la segunda se compuso de una mayoría mestiza. La ausencia de referencia a esta categoría étnica en los nombramientos sugiere que los mestizos que descendían de padres o de abuelos conquistadores estaban perfectamente integrados en la oligarquía local y que su origen étnico llegaba a “desaparecer” o “borrarse” rápidamente. ${ }^{86}$ Lo mismo ocurrió en Yucatán, donde la identidad mestiza de los intérpretes no aparece ni en sus nombramientos ni en sus probanzas de méritos y servicios, sino en denuncias que algunos vecinos enviaron al Consejo de Indias. ${ }^{87} \mathrm{~A}$ este respecto, conviene señalar que, si bien en 1588 la corona mandó una cédula real al gobernador de Yucatán recomendándole que, "habiendo españoles suficientes que puedan servir allí de intérpretes, provea en ellos estos oficios", poco después el Consejo dio confirmaciones de oficio tanto al maya Gaspar Antonio Chi como al mestizo Antonio Nieto. ${ }^{88}$

El rastreo de la identidad étnica y del origen social de los intérpretes permite medir, asimismo, la extensión del bilingüismo entre la población de la capital del virreinato novohispano. Por lo general, la historiografía ha insistido en el proceso de castellanización de los indios "ladinos", haciendo especial hincapié en el destacado papel educativo desempeñado por el clero regular con los hijos de la nobleza indígena. ${ }^{89}$ No obstante, es importante

\footnotetext{
85 Sobre esta política, véase Sarabia Viejo, Don Luis de Velasco, pp. 221-237 y Ruiz Medrano, Reshaping New Spain, pp. 95-115.

${ }_{86}$ Sobre estas cuestiones, véanse RAPPAPORT, The Disappearing Mestizo y Canuto Castillo, "Españoles descendientes de aquéllos [indios]”.

${ }^{87}$ Cunill, “Los intérpretes de Yucatán”, pp. 374-375.

${ }^{88}$ Cunill, “Los intérpretes de Yucatán”, pp. 375-377.

89 Véanse, entre otros, Aguilar Moreno, “The Indio Ladino”, pp. 149-184; Pérez-Rocha y Tena, La nobleza indígena; Cunill, "La alfabetización de los mayas"; Alaperrine-Bouyer, La educación de las élites.
} 
subrayar que fueron numerosos los conquistadores españoles y sus hijos, quienes aprendieron a hablar e incluso a escribir el náhuatl. Como se ha demostrado, este fenómeno se debió a tres factores principales que, en algunos casos, se combinaron: la mediación de las esposas indígenas de algunos españoles, el llegar joven o nacer en México y, finalmente, el trato cotidiano con la población autóctona. Abundan en este sentido los datos personales relativos a los testigos presentados por Juan Freyle en su probanza de 1554. En efecto, el peticionario llamó a declarar a españoles bilingües que fueran capaces de atestiguar de sus habilidades en náhuatl. Así pues, Juan de Alcalá, solicitador del fisco de 25 años que llegó a Nueva España cuando apenas tenía dos, afirmó "entende[r] bien la lengua de los indios mexicanos". Del mismo modo, Francisco Muñoz, que se trasladó a México a los 15 años, dijo que sabían que "Juan Freyle entiende muy bien la lengua mexicana $[. .$.$] porque este testigo entiende muy bien la$ dicha lengua". Finalmente, Diego Hernández Nieto, que tenía 50 años en 1554 y que llevaba 28 en Nueva España, declaró que "entiende la lengua mexicana razonablemente y que sabe que el dicho Juan Freyle es muy buena lengua mexicana". ${ }^{0}$ No cabe duda, por ende, de que el bilingüismo estuvo muy generalizado tanto entre los españoles como entre sus hijos, ya fueran éstos mestizos o criollos. ${ }^{91}$ De hecho, este proceso no fue exclusivo del Valle de México, puesto que Farriss compara la castellanización de los mayas con la "mayanización" de los criollos de Yucatán, que estuvo favorecida por el hecho de que los hijos de los colonos fueron criados por nodrizas indígenas. ${ }^{92}$ Muñoz Arbeláez también menciona varios ejemplos de conquistadores españoles,

\footnotetext{
90 AGI, $A M$, 96, R. 3, ff. 4v.-5v. y 10v. Probanza de Juan Freyle (1554).

${ }^{91}$ Sobre estas cuestiones, véanse también BraIN, "Aprendizaje de lenguas indígenas” y Nesvig, "Spanish Men, Indigenous Language”. Acerca de la propensión de los mestizos y mulatos para servir de mediadores lingüísticos informales en Nueva España véase SCHWALLER, “The Importance of Mestizos”. 92 FARriss, “Conquista y cultura”, pp. 208-211.
} 
de caciques muiscas y de mestizos perfectamente bilingües en el Nuevo Reino de Granada del siglo xvi. ${ }^{93}$

Los nombramientos que se otorgaron a los intérpretes de la Audiencia de México a partir de 1555 contienen interesantes datos acerca del salario de aquellos oficiales. Se estipuló que cobrarían 200 pesos de oro común anuales procedentes de las penas de estrados y que se les libraría esta remuneración por los tercios del año. A cambio, los intérpretes debían comprometerse a no recibir "ni cohecho ni otra cosa alguna que se le diese". Sin embargo, además del mencionado salario, los titulares podían cobrar "derechos moderados" a los demandantes que solicitaran sus servicios. Así, por ejemplo, el presidente y los oidores de la Audiencia mandaron a Juan de Riberol que:

[...] use bien y fielmente con todo secreto el dicho cargo y que interpretase verdad de todo lo que le fuere mandado sin menguar cosa alguna y que no llevare derechos demasiados ni cohecho ni otra cosa alguna que se le diese, el cual prometió de lo así hacer y cumplir so cargo del juramento y los dichos señores le señalaron de salario por cada un año 200 pesos de oro común en penas de estrados los cuales les sean pagados por los tercios del año. ${ }^{94}$

Las expresiones "no llevar derechos demasiados" o "derechos moderados" sin duda se referían al arancel fijado por el virrey Mendoza en sus ordenanzas de 1548. Éste dispuso, en efecto, que los intérpretes no podían aceptar presentes ni contratar con los indios, pero que cobrarían por la traducción de las declaraciones de cada testigo dos tomines y que, por otro lado, se les daría un peso de oro común "cada un día que salieren de la ciudad". ${ }^{95}$

${ }_{93}$ Muñoz Arbeláez, Costumbres en disputa.

${ }_{94}$ AGN, RCD, vol. 1, exp. 68, f. 75v. Nombramiento de Juan de Riberol (1555).

${ }^{95}$ Mendoza, Ordenanzas, f. 30v. 
Este tratamiento difiere de lo que ocurrió en la gobernación de Yucatán, donde se prohibió que los intérpretes cobrasen derechos a los indígenas. Éstos debían contentarse, en efecto, con un salario que se elevó a 100 pesos de oro común anuales a partir de 1560 y que fue acrecentado a 200 pesos desde 1577. En un nombramiento el gobernador Francisco de Gijón mandó, por ejemplo, que "por la interpretación de los dichos negocios por escrito y por palabra [...] no habéis de llevar de los dichos indios paga ni otra cosa alguna" ${ }^{96}$ Otra notable diferencia entre México y Yucatán fue la aplicación de una política salarial asimétrica para el único intérprete indígena que sirvió en esta gobernación. Así pues, el maya Gaspar Antonio Chi tan sólo cobró 80 pesos anuales de 1580 a 1593, fecha en la que la corona decidió aumentar su remuneración para que alcanzase los 200 pesos que se daban a los demás titulares. ${ }^{97} \mathrm{~A}$ este propósito, cabe señalar que si en 1566 la Audiencia otorgó a Juan Juárez, "alguacil e intérprete" indígena de la lengua mixteca, una ayuda de costa de 30 pesos de oro común, fue probablemente porque éste solo prestaría sus servicios cuando llegaran a México casos en esta lengua. Esta remuneración también incluía su trabajo "por el cargo que tiene de la capilla". ${ }^{98}$

En todo caso, no deja de ser sorprendente la igualdad de salario entre los intérpretes de la Audiencia de México y los de la gobernación de Yucatán, puesto que la carestía había de ser más importante en la capital del virreinato. Es probable, por lo tanto, que a ello se debiera la posibilidad de que los primeros pudiesen cobrar derechos a los indígenas, mientras que se les estaba prohibido a los segundos. También conviene señalar que varios intérpretes de

\footnotetext{
${ }_{96}$ AGI, $A M, 107$, R. 3. Nombramiento de intérprete a Diego de Vargas (1577). ${ }^{77}$ Cédula real a favor de Gaspar Antonio Chi, Elvas, 22 de diciembre de 1580, y cédula real a favor de Gaspar Antonio Chi, San Lorenzo, 20 de octubre de 1593, en Solís Robleda y Bracamonte y Sosa, Cedulario, pp. 386 y 495-496. 98 AGN, $R C D$, vol. 1, exp. 321, f. 289v. Que se le pague a Juan Juárez, indio, 30 pesos de oro común por el cargo que tiene de la capilla (1566).
} 
México recibieron otras mercedes, especialmente la de gozar de cargos de tenientes de corregidor ("tenientazgos"). En Reshaping New Spain, Ruiz Medrano apunta que el tributo correspondiente al oficio de teniente de corregidor de un pueblo llamado Talasco debió de servirle de salario al intérprete Pedro García en la década de $1530 .{ }^{99}$ En realidad no se trató de un caso aislado, puesto que los nombres de varios intérpretes de la Audiencia de México aparecen en la lista de quienes recibieron cargos de tenientes de corregidores de mano del virrey Antonio de Mendoza entre 1535 y 1546. Así, Álvaro de León fue teniente de Cuyceo en 1535 y de Metateyuca de 1538 a 1543, Antonio Ortiz lo fue de Chinanta en 1537 y 1540-1543, Álvaro de Zamora de Chiautla de 1537 a 1541, Juan Gallego de Cinacua en 1545 y 1546, y Tomás de Rijoles de Tepeapulco de 1540 a 1543 y en $1545 .{ }^{100}$

Esta tradición perduró en el gobierno de don Luis de Velasco. En efecto, en un parecer de 1560 este virrey explicaba que pensaba otorgar a Álvaro de Zamora un tenientazgo de un valor de 120 pesos de renta anual. Con esta merced y con el salario de intérprete, pretendía compensar a Zamora por la pérdida de su encomienda, un "pueblo en la costa del sur que se dice Mazatlán, el tributo del cual le podrá valer hasta 100 pesos" que había recibido en remuneración de sus servicios en la conquista de México. ${ }^{101}$ Juan Grande, por su parte, gozaba del tenientazgo del partido de Chietla en la década de 1580 y, a su vez, Francisco de Leiva recibió 100 pesos de salario como teniente del pueblo de Totolapa en 1606 y 1607. 102 Pedro López Barahona

99 Ruiz Medrano, Reshaping Nerw Spain, p. 26.

100 AGI, J, 258. Relación de los corregimientos que se han proveído en esta Nueva España de los pueblos que están en su Real Corona por el ilustrísimo don Antonio de Mendoza. Este documento fue transcrito y publicado por Ruiz Medrano, Reshaping New Spain, pp. 265-298.

101 AGI, $A M, 205$, N. 33. Parecer de la Audiencia de México (ca. 1560).

${ }^{102}$ AGN, T, vol. 2991, exp. 40, f. 1. Prorrogación a Juan Grande, intérprete, en el tenientazgo del partido de Chietla, por quinto año de dos meses (1591). AGN, $R C D$, vol. 5, exp. 457, f. 110v. Ordenando que por otro año se conceda 
también pidió un "tenientazgo de costa en 1580 ", pero no tenemos constancia de si le fue otorgado o no. ${ }^{103}$ Por consiguiente, si se suman los salarios de 200 pesos a las mercedes de 100 o 120 pesos, que correspondían a los cargos de tenientes de corregidor, se llega a la conclusión de que la mayoría de los intérpretes de la Audiencia de México solía cobrar como mínimo 300 pesos anuales por sus servicios.

Sin embargo, al igual que los intérpretes de Yucatán, los titulares de la Audiencia de México encontraron serias dificultades para que les fuesen debidamente pagados sus salarios. De hecho, el retraso en el cobro de sus emolumentos fue precisamente el motivo de las dos quejas que Juan Gallego presentó en nombre de los intérpretes de México en 1563 y 1567. En la primera denunció que "se nos deben de nuestros salarios muchos pesos de oro de muchos años corridos" y pidió que los "salarios de los intérpretes sean preferidos a otros cualesquiera libranzas de penas de cámara y estrados". Pero los oficiales reales contestaron que "de presente no hay de qué pagar" ${ }^{104}$ Por consiguiente, unos años más tarde Juan Gallego volvió a interpelar a las autoridades declarando que "a nosotros [los intérpretes de la Real Audiencia] ha más de seis años que no se nos paga ninguna cosa de los salarios que tenemos situados en penas de cámara y estrados a cuya causa padecemos mucha necesidad". ${ }^{105}$ La Audiencia mandó a los oficiales reales un auto en el que citó un capítulo de las ordenanzas de 1563 en que la corona establecía una relación explícita entre el salario y el correcto desenvolvimiento del cargo

100 pesos de salario como teniente del pueblo de Totolapa a Francisco de Leiva intérprete de la Real Audiencia (1607).

${ }_{103}$ AGN, IV, 6718, exp. 15. Pedro López Barahona, hijo de conquistador e intérprete de la Real Audiencia suplica a vuestra excelencia sea servido de una merced de un tenientazgo de costa (1580).

${ }^{104}$ AGI, $A M, 97$, R. 5, 7 fs. Probanza de Juan Gallego y de los intérpretes de las lenguas de Nueva España (1567).

${ }^{105}$ AGI, $A M, 97$, R. 5, 7 fs. 
de intérprete. Estipulaba que se pagaran a los intérpretes "sus salarios de nuestra Hacienda porque de esta manera servirán mejor y cesarán algunos inconvenientes que haya a causa de ser mal pagados" y que fueran "preferidos en las pagas de sus salarios a todas las libranzas que estuvieren hechas y se hicieren en las dichas penas de cámara". ${ }^{106}$

\section{CONSIDERACIONES FINALES}

Las visitas de la primera mitad del siglo XvI, al poner de manifiesto las numerosas exacciones cometidas por los intérpretes de la Real Audiencia de México, condujeron a una mayor concientización de la problemática lingüística en el campo de la justicia. Ello no debió ser ajeno a la voluntad de institucionalización del oficio de intérprete presente en las ordenanzas promulgadas por el virrey don Antonio de Mendoza en 1548. No obstante, si nos fiamos de las fechas de los primeros nombramientos de intérpretes que se encuentran en el Archivo General de la Nación de México, parece que fue bajo el mando del virrey don Luis de Velasco cuando realmente se puso en práctica esta voluntad política. En efecto, a partir de 1555 contamos con una serie casi completa de nombramientos de los titulares del oficio. Es probable, además, que el virrey Velasco aprovechara los factores demográficos para renovar el cuerpo de titulares que servían esta función. Así, podemos comprobar que, mientras que los antiguos conquistadores casados con mujeres indígenas monopolizaron el cargo en la primera mitad del siglo xvi, a partir de 1555 éstos fueron paulatinamente sustituidos por mestizos y, en menor medida, por criollos. Sin embargo, queda claro que el cargo de intérprete siguió estrechamente vinculado con el grupo de beneméritos, puesto que casi todos los mestizos que ocuparon el oficio en la segunda mitad del siglo xvi tenían un

${ }_{106}$ AGI, $A M, 97$, R. 5, 7 fs. 
padre o un abuelo conquistador. Esta característica explica por qué varios intérpretes de la Audiencia de México, además de su salario de 200 pesos anuales, también gozaron de tenientazgos de un valor de entre 100 y 120 pesos. En estas circunstancias, fuera de la notable excepción de Hernando de Tapia, pocos fueron los indígenas que llegaron a ocupar este cargo. Además, por lo general, los titulares indígenas fueron reclutados para realizar labores de interpretación de lenguas autóctonas diferentes del náhuatl, como ocurrió con Pablo Pérez, intérprete de otomí, y con Juan Juárez, que sirvió como alguacil y, de manera puntual, como intérprete de mixteco.

\section{SIGLAS Y REFERENCIAS}

AGI, $E$ Archivo General de Indias, fondo Escribanía, Sevilla, España.

AGI, $J$ Archivo General de Indias, fondo Justicia, Sevilla, España.

AGI, $A M$ Archivo General de Indias, fondo Audiencia de México, Sevilla, España.

AGI, PR Archivo General de Indias, fondo Patronato Real, Sevilla, España.

AGN, C Archivo General de la Nación, fondo Civil, Ciudad de México, México.

AGN, HJ Archivo General de la Nación, fondo Hospital de Jesús, Ciudad de México, México.

AGN, I Archivo General de la Nación, fondo Indios, Ciudad de México, México.

AGN, IV Archivo General de la Nación, fondo Indiferente Virreinal, Ciudad de México, México.

AGN, RCD Archivo General de la Nación, fondo Reales Cédulas Duplicadas, Ciudad de México, México.

AGN, $T$ Archivo General de la Nación, fondo Tierras, Ciudad de México, México.

Aguilar Moreno, Manuel, “The Indio Ladino as a Cultural Mediator in the Colonial Society”, en Estudios de Cultura Nábuatl, 33 (2002), pp. 149-184.

Alaperrine-Bouyer, Monique, La educación de las élites indígenas en el Perú colonial, Lima, Instituto Francés de Estudios Andinos, Instituto Riva Agüero, 2007. 
Bаттсоск, Clementina, y Sergio Bотта (eds.), Acerca de la (des)memoria y su construcción en Mesoamérica y Andes, México, Ediciones Quivira, 2015.

Bernand, Carmen (comp.), Descubrimiento, conquista y colonización de América a quinientos años, México, Fondo de Cultura Económica, 1994.

BoraH, Woodrow, El Juzgado General de Indios en la Nueva España, México, Fondo de Cultura Económica, 1985.

Brain, Cecilia, “Aprendizaje de lenguas indígenas por parte de españoles en Nueva España en los primeros cien años después de la conquista”, en Colonial Latin American Review, 19: 2 (2010), pp. 279-300.

Burns, Kathryn, Into the Archive. Writing and Power in Colonial Peru, Durham y Londres, Duke University Press, 2010.

Canuto Castillo, Felipe, “'Españoles descendientes de aquéllos [indios]’. Nietos españoles de caciques indios", en Nuevo Mundo Mundos Nuevos, puesto en línea el 13/02/2017, consultado el 22/02/2017. URL: http://nuevomundo.revues.org/70408.

Carrasco, Pedro, "Indian-Spanish Marriages in the First Century of the Colony”, en Schroeder, Wood y Haskett (eds.), 1997, pp. 87-104.

Christensen, Mark Z., "The Use of Nahuatl in Evangelization and the Ministry of Sebastian”, en Ethnohistory, 59:4 (2012), pp. 691-711.

Сово Betancourt, Juan Fernando, "Colonialism in the Periphery: Spanish Linguistic Policy in New Granada, 1574-1625”, en Colonial Latin American Review, 23: 2 (2014), pp. 118-142.

Connell, William F., After Moctezuma: Indigenous Politics and Self-Government in Mexico City, 1524-1730, Norman, Oklahoma Press, 2011.

Cunill, Caroline, "Justicia e interpretación en sociedades plurilingües: el caso de Yucatán en el siglo Xvı”, en Estudios de Historia Novohispana, 52 (2015), pp. 18-28.

Cunill, Caroline, "Los intérpretes de Yucatán y la Corona española: negociación e iniciativas privadas en la fragua del Imperio ibérico, siglo xvı”, en Colonial Latin American Historical Review, Second Series, 1: 4 (2013), pp. 361-380. 
Cunill, Caroline, "La alfabetización de los mayas yucatecos y sus consecuencias sociales (1545-1580)", en Estudios de Cultura Maya, 31 (2008), pp. 163-192.

Documentos cortesianos, edición de José Luis Martínez, México, Fondo de Cultura Económica, Universidad Nacional Autónoma de México, 1991, 4 volúmenes.

Dorantes de Carranza, Baltazar, Sumaria relación de las cosas de la Nueva España con noticia individual de los descendientes legítimos de los conquistadores y primeros pobladores españoles, México, Imprenta del Museo Nacional, 1902.

Dueñas, Alcira, "The Lima Indian Letrados: Remaking the República de Indios in the Bourbon Andes”, en The Americas, 72: 1 (2015), pp. 55-75.

Durston, Alan, Pastoral Quechua: The History of Christian Translation in Colonial Peru, 1550-1650, Notre Dame, IN, University of Notre Dame Press, 2007.

Encinas, Diego de, Cedulario Indiano, Madrid, Ediciones de Cultura Hispánica, 1946.

Estenssoro, Juan Carlos, y César Itier, "Langues indiennes et Empire dans l'Amérique du Sud coloniale", en Mélanges de la Casa de Velázquez, 45: 1 (2015).

Farriss, Nancy, “Conquista y cultura: los mayas de Yucatán”, en Bernand (comp.), 1994, pp. 208-211.

Gayol, Víctor, Laberintos de justicia. Procuradores, escribanos y oficiales de la Real Audiencia de México (1750-1812), Zamora, El Colegio de Michoacán, 2007, 2 volúmenes.

Grunberg, Bernard, Dictionnaire des conquistadores espagnols, París, L'Harmattan, 2001.

Hanks, William F., Converting Words. Maya in the Age of the Cross, Berkeley, California, University of California Press, 2010.

Herzog, Tamar, Mediación, archivos y ejercicio: los escribanos de Quito, siglo XVIII, Fráncfort del Memo, Vittorio Klostermann, 1996. 
Jurado, Carolina, "Don Pedro de Dueñas, indio lengua. Un estudio de caso de la interpretación lingüística andino-colonial en el siglo xvı", en Anuario del Archivo y Biblioteca Nacional de Bolivia, 16 (2010), pp. 285-309.

KartTunen, Frances, Between Worlds: Interpreters, Guides and Survivors, New Brunswick, Rutgers University Press, 1994.

Kellogg, Susan, Law and Transformation of Aztec Culture, 1500-1700, Norman, University of Oklahoma Press, 1995.

Machuca, Paulina, Intérpretes y trasuntos, siglos XVI-XVII: el caso de Colima de la Nueva España, Colima, Archivo Histórico del Municipio de Colima, Archivo de Letras, Artes, Ciencias y Tecnologías, 2009.

Martínez Peñalosa, María Teresa, "Noble purépecha, intérprete en el Juzgado General de Indios", en Uandani Mensaje Cultural Michoacano, 6 y 7 (1982), pp. 22-24.

Matthew, Laura E. y Sergio F. Romero, "Náhuatl and Pipil in Colonial Guatemala: a Central American Counterpoint", en Colonial Latin American Review, 59:4 (2012), pp. 765-783.

Mendoza, Antonio de, Ordenanzas y compilación de leyes por el muy Ilustre Señor don Antonio de Mendoza, Madrid, Ediciones de Cultura Hispánica, 1945.

Mijares Ramírez, Ivonne, Escribanos y escrituras públicas en el siglo XVI: el caso de la Ciudad de México, México, Universidad Nacional Autónoma de México, 1997.

MuÑoz Arbeláez, Santiago, Costumbres en disputa. Los muiscas y el Imperio español en Ubaque, siglo XVI, Bogotá, Universidad de los Andes, 2015.

Nansen Díaz, Eréndira, "Los intérpretes jurados como auxiliares de la administración de justicia colonial”, en Paredes Martínez y Terán (coords.), 2003, pp. 173-184.

Nesvig, Martin, "Spanish Men, Indigenous Language, and the Informal Interpreters in Postcontact Mexico", en Ethnohistory, 59: 4 (2012), pp. 739-764.

Ordóñez Cifuentes, José Emilio Rolando (coord.), El derecho a la lengua de los pueblos indígenas. XI Jornadas Lascasianas, México, Universidad Nacional Autónoma de México, 2003. 
Owensby, Brian P., Empire of Law and Indian Justice in Colonial Mexico, Stanford, Stanford University Press, 2008.

Paredes Martínez, Carlos y Marta Terán (coords.), Autoridad y gobierno indígena en Michoacán, Zamora, El Colegio de Michoacán; Morelia, Michoacán, México, Universidad Michoacana de San Nicolás de Hidalgo, Centro de Investigaciones y Estudios Superiores en Antropología Social, Instituto Nacional de Antropología e Historia, 2003.

Paso y Troncoso, Francisco del, Epistolario de Nueva España, México, Antigua Librería Robredo, 1939-1942, 16 volúmenes.

Payas, Gertrudis y José Manuel Zavala (eds.), La mediación lingüistico-cultural en tiempos de guerra. Cruce de miradas desde España y América, Temuco, Chile, Ediciones la Universidad Católica de Temuco, 2012.

Pérez-Rocha, Emma y Rafael Tena, La nobleza indígena del centro de México después de la Conquista, México, Instituto Nacional de Antropología e Historia, 2000.

Poole, Stafford, Pedro Moya de Contreras: Catholic Reform and Royal Power in New Spain, 1571-1591, Berkeley, University of California Press, 1987.

Procesos de indios idólatras y hechiceros, edición de Luis González Obregón, México, Publicaciones del Archivo General de la Nación, 1912.

Puente Luna, José Carlos de la, “The Many Tongues of the King: Indigenous Language Interpreters and the Making of the Spanish Empire", en Colonial Latin American Review, 23: 2 (2014), pp. 143-170.

Ramos, Gabriela y Yanna Yannakakis (eds.), Indigenous Intellectuals: Knowledge, Power, and Colonial Culture in Mexico and the Andes, Durham y Londres, Duke University Press, 2014.

Rappaport, Johanne, The Disappearing Mestizo. Configuring Difference in the Colonial New Kingdom of Granada, Durham y Londres, Duke University Press, 2014.

Romero Galván, José Rubén, Los privilegios perdidos: Hernando Alvarado Tezozómoc, su tiempo, su nobleza y su Crónica mexicana, México, Universidad Nacional Autónoma de México, 2003. 
Rovira Morgado, Rossend, San Francisco Padremeb: el temprano cabildo indio y las cuatro parcialidades de México-Tenochtitlan (1549-1599), Madrid, Consejo Superior de Investigaciones Científicas, 2017.

Rovira Morgado, Rossend, “La 'Casa de Tapia': imaginario público y reelaboración histórica en torno a un inmueble prehispánico de cuadrante de San Pablo Teopan en México-Tenochtitlan (siglo xvi)", en BAтTcock у ВоттA (eds.), 2015, pp. 282-309.

Ruiz Medrano, Ethelia, Mexico's Indigenous Communities. Their Lands and Histories, 1500-2010, Boulder, Colorado, University Press of Colorado, 2010.

Ruiz Medrano, Reshaping New Spain. Government and Private Interests in the Colonial Bureaucracy, 1531-1550, Boulder, Colorado, University Press of Colorado, 2006.

Ruiz Medrano, Ethelia y Perla Valle, "Los colores de la justicia: códices jurídicos del siglo xvi en la Biblioteca Nacional de Francia", en Journal de la Société des Américanistes, 83: 2 (1998), pp. 228-235.

Sarabia Viejo, María Justina, Don Luis de Velasco, virrey de Nueva España (1550-1564), Sevilla, Consejo Superior de Investigaciones Científicas, Escuela de Estudios Hispanoamericanos, 1978.

Schroeder, Susan, Stephanie Wood y Robert Haskett (eds.), Indian Women of Early Mexico, Norman, University of Oklahoma Press, 1997.

Schwaller, John F., "The Expansion of Nahuatl as a Lingua Franca among Priests in Sixteenth-Century Mexico", en Ethnohistory, 59: 4 (2012), pp. 675690.

Schwaller, Robert C., "The Importance of Mestizos and Mulatos as Bilingual Intermediaries in Sixteenth-Century New Spain”, en Ethnobistory, 59: 4 (2012), pp. 713-738.

Solano, Francisco de, El intérprete: uno de los ejes de la aculturación, Valladolid, Simposio Hispanoamericano de Indigenismo Histórico, 1975.

Solís Robleda, Gabriela y Pedro Bracamonte y Sosa, Cedulario de la dominación española en Yucatán, siglo XVI, México, Centro de Investigaciones y Estudios Superiores en Antropología Social, 2011. 
YANNAKAKIs, Yanna, "Making Law Intelligible: Networks of Translation in Mid-Colonial Oaxaca”, en Ramos y Yannakakis (eds.), 2014, pp. 79-106.

Yannakakis, Yanna, The Art of Being in-Between. Native Intermediaries, Indian Identity, and Local Rule in Colonial Oaxaca, Durham y Londres, Duke University Press, 2008.

Yrigoyen FajARdo, Raquel, Justicia y multilingüismo. Pautas para alcanzar una justicia multilingüe en Guatemala, Guatemala, Programa de Justicia Checchi, 2001.

Zavala, Silvio, Poder y lenguaje desde el siglo XVI, México, El Colegio de México, 1996. 